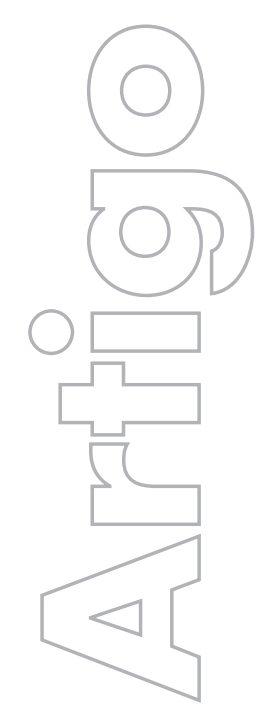

revista

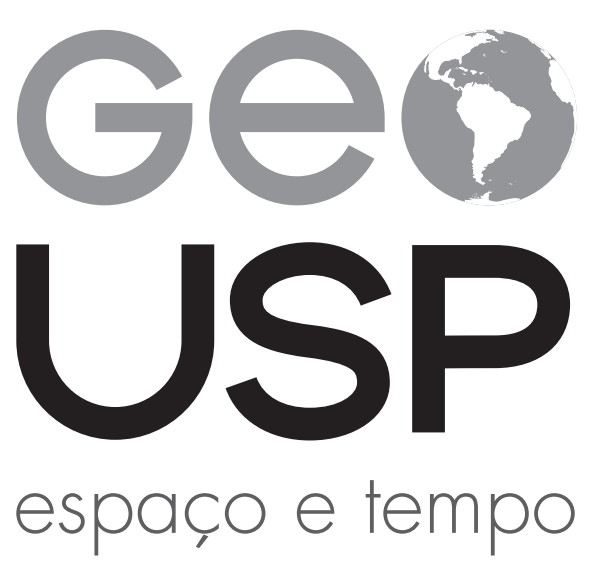

Volume $23 \cdot n^{\circ} 1$ (2019)

ISSN 2179-0892
Geografias das ausências e geografias das
emergências

Cristiano Quaresma de Paula UFRGS e-mail: cqpgeo@gmail.com

p. $095-111$

Como citar este artigo:

PAULA, C. Q. Geografias das ausências e geografias das emergências. Geousp - Espaço e Tempo (Online), v. 23, n. 1, p. 095-111, abr. 2019. ISSN 2179-0892.

Disponível em: https://www.revistas.usp.br/geousp/article/ view/150177. doi: https://doi.org/10.11606/issn.2179-0892. geousp.2019.150177.

\section{(c) (i) (5)}

Este artigo está licenciado sob a Creative Commons Attribution 4.0 License. 


\title{
Geografias das ausências e geografias das emergências
}

\section{Resumo}

Geografias das ausências e geografias das emergências convocam a refletir em que medida os estudos dos geógrafos reafirmam invisibilidades de sujeitos e territórios. Nesse contexto, entende-se que é preciso enaltecer as experiências do local que resiste às influências do global. Assim, é possível identificar as ausências produzidas na geografia, que enaltece o avanço dos paradigmas da modernização sobre os territórios tradicionais, bem como promover emergências destacando o processo de retomada da autonomia no/do território por comunidades tradicionais.

Palavras-chave: Geografia brasileira. Territórios tradicionais. Território da modernização. Invisibilidades.

\section{Geographies of Absences and Geographies of Emergencies}

\begin{abstract}
Geographies of Absences and Geographies of Emergencies provoke reflection on the extent to which the studies of geographers reaffirm invisibilities of subjects and territories. In this context, it is understood that it is necessary to extol the experiences of the place, which resists the influences of the global. Thus, it is possible to identify the absences produced in Geography, which exposes the advance of the paradigms of modernization over the traditional territories. As well as promoting emergencies, highlighting the process of regaining autonomy in the territory by traditional communities.
\end{abstract}

Keywords: Brazilian geography. Traditional territories. Territory of modernization. Invisibilities.

\section{Introdução}

Questionar o quanto a Geografia promove de ausências expõe um campo de tensões. Isso porque se questiona o próprio fazer científico do ponto de vista epistemológico e metodológico. Da mesma forma, promover emergências na Geografia é um desafio, pois exige do 
geógrafo abertura às problemáticas e aos sujeitos sociais que estavam/estão invisibilizados. Nessa leitura geográfica, a dialógica entre o enfrentamento às ausências e a promoção de emergências expõe impactos, disputas e conflitos nos territórios. Esse embate se dá entre sujeitos sociais (invisibilizados) e atividades econômicas que se impõem sobre o território e evidenciam as faces da modernização.

Em Geografia(s) da pesca artesanal brasileira, Paula (2018) fomentou essa discussão no âmbito das dissertações e teses de geógrafos brasileiros. Procurou compreender a produção de ausências que resultam nas faces da modernização, as quais definiu a partir do diálogo com sujeitos e movimentos sociais: degradação, sobre-exploração e limite ao acesso e a expropriação da terra. Percebeu que a invisibilidade social desses sujeitos - no caso, os pescadores artesanais - também se expressa na pesquisa em Geografia, que, assim, também promove ausências. Contudo, na medida em que os sujeitos sociais são inseridos na pesquisa geográfica, sobretudo nas abordagens que expõem as faces da modernização, promovem-se emergências.

Destaca-se que essa compreensão a partir da Geografia está inspirada na proposição de Boaventura Santos (2007) de sociologia das ausências e sociologia das emergências. Contudo, além de adotar a abordagem do autor, de expandir o presente e contrair o futuro, também se entende que é necessário enaltecer a experiência local para reduzir a influência do global. No caso da referida tese sobre a pesca artesanal, se evidencia o embate entre território tradicional e território da modernização, e expõem a constituição de um território de luta das comunidades tradicionais.

Colocando em destaque a questão territorial na análise das ausências, compreende-se que o território da modernização avança sobre territórios tradicionais, como argumenta Raffestin (2012), por meio do estabelecimento de paradigmas que se afirmam a partir de sintagmas. Estabelecendo o diálogo com as "monoculturas" de Boaventura Santos (2002, 2011) se entende como paradigmas que permitem o avanço da modernização sobre os territórios tradicionais: saber único, tempo sincrônico, inferioridade dos grupos e territórios, escala global, e produtivismo.

Para superar as ausências é necessário, então reestabelecer a autonomia do território tradicional, promovendo a emergências de sujeitos, grupos e movimentos sociais. Dialoga-se então com as "ecologias" de Boaventura Santos $(2002,2011)$ para propor a recuperação da autonomia do território tradicional, no que se refere aos saberes, multitemporalidades, reconhecimentos das diferenças, escala do local e produção tradicional.

$\mathrm{Na}$ constituição da proposta de análise da tese que sustenta este artigo, tomaram-se como base os princípios do pensamento complexo apontados por Morin (1990): dialógico, recursão organizacional e hologramático. Nessa tese, Paula (2018) faz análises de conteúdo (Bardin, 2011) de 71 dissertações e teses que abordam a pesca artesanal na Geografia brasileira, bem como representações cartográficas. Analisou ainda conteúdos denunciais do website do Movimento dos Pescadores e Pescadoras Artesanais (MPP) e do Relatório de Conflitos Socioambientais (Tomáz; Santos, 2016), do Conselho Pastoral da Pesca (CPP). Também conduziu trabalhos de campo em reuniões de movimentos sociais relacionados com a pesca artesanal, sobretudo o MPP e o Fórum Delta do Jacuí, e com grupos de pesquisa da Geografia brasileira que priorizam a pesca artesanal em seus estudos. 
Diante do exposto, com base nas discussões promovidas em Geografia(s) da pesca artesanal brasileira (Paula, 2018), o artigo pretende estabelecer um diálogo teórico sobre a produção de ausências na/pela pesquisa geográfica, bem como apontar tendências de promoção de emergências, enaltecendo o embate entre territórios tradicionais e territórios da modernização.

\section{A expressão do/no território das ausências e emergências}

A compreensão de ausências e emergências no âmbito da Geografia provoca a pensar as mesmas na dimensão espacial. Isso tem sido assumido por diversos geógrafos que tem tratado as "invisibilidades", cujas abordagens têm em comum a compreensão de que determinados sujeitos, por meio de processos sociais, são invisibilizados no espaço. Assim, as abordagens que enaltecem os "até então invisíveis" expõem sua expressão no espaço (lugar, território, paisagem etc.).

Como ensina Milton Santos (2006), as ausências são amplamente produzidas, inclusive no meio científico. Dessa forma, cabe compreender que tais "invisibilidades" sociais decorrem também da ausência desses sujeitos nos estudos dos geógrafos. Compreende-se a impossibilidade de tratar de todas as dimensões em determinada pesquisa, contudo, questiona-se o porquê da predileção destas por determinada classe ou grupo (dependendo do método). Entende-se que elas são produzidas amplamente na Geografia e decorrem da promoção do discurso sempre a partir do dominante, no privilégio a alguma cultura, e na promoção de determinada racionalidade.

Silva (2016) toma o exemplo dos "vazios demográficos", como promoção de invisibilidades pelos geógrafos. Entende-se que os vazios demográficos correspondem à compreensão do espaço a partir da lógica dominante, no caso a industrialização e a urbanização, expondo um discurso comprometido com o desenvolvimento econômico (Santos, B., 2002), por meio da modernização. Tal compreensão exclui das análises todos os sujeitos que não estão inseridos nesse processo de desenvolvimento e não correspondem ao projeto de modernização proposto. Além disso, são sujeitos que muitas vezes não se explicam por meio da razão da ciência geográfica moderna, por não separarem sociedade de natureza e por estabelecerem outras lógicas de relações sociais. Por isso, quando identificados (não analisados), são apresentados como arcaicos, estagnados, miseráveis e obstáculos para o progresso da sociedade, uma vez que o ponto de vista se estabelece a partir do moderno.

Contudo, deve-se questionar sobre a modernização que provoca invisibilidades dos sujeitos sociais e ausências nas análises geográficas do espaço. Nesse sentido, é fundamental retomar a noção de "colonialidade do poder" que se efetiva por meio de dispositivos, no âmbito dos Estados, de criação de identidades homogêneas por meio de políticas de subjetivação, bem como na manutenção da governabilidade a partir das potencias hegemônicas do sistema-mundo moderno/colonial (Castro-Gómez, 2005). Isso se dá em contextos que Boaventura Santos (2007) chama de regresso colonizador, na ressurgência de formas de governo colonial tanto nas cidades metropolitanas quanto naquelas anteriormente sujeitas ao colonialismo europeu.

Dessa forma, são inseparáveis os movimentos das ciências e da sociedade, a ponto de Quijano (2005) considerar a colonialidade do poder e do saber. Nesse sentido, Santos, Meneses e Nunes (2006) destacam a necessidade de construir outras versões da história e da ciência, para evidenciar histórias globais e multiculturais do conhecimento e superar a colonia- 
lidade do saber. Nessa perspectiva entende-se a necessidade de evidenciar outas Geografias do vivido, para renovar a ciência geográfica, abrindo-a para outros sujeitos e problemáticas que não correspondem, e contestam, a racionalidade dominante - moderna/ocidental. Assim, devem-se superar no âmbito da Geografia os efeitos da razão metonímica e proléptica de que fala Boaventura Santos (2002).

Assim, a Geografia deve abrir-se para as inúmeras racionalidades de uso e apropriação do espaço. Isso significa reconhecer saberes e práticas, bem como vínculos singulares que determinados grupos estabelecem com o espaço geográfico. Tais racionalidades promovem na Geografia o novo, apresentando soluções para problemáticas que não foram resolvidas pelo pensamento científico - antes criadas por este - e que promovem reflexões epistemológicas na própria Geografia. De outro lado, a Geografia deve pensar o futuro para além do que se evidencia, reconhecendo possibilidades de conversão e rompimento com a linearidade do presente. Esse futuro se expõe no diálogo com outras perspectivas de mundo.

Boaventura Santos (2007) propõe criar um espaço-tempo para o conhecimento e a valorização da experiência social, que se manifesta no presente. Para o autor, é necessário expandir o presente e contrair o futuro. Na leitura geográfica que se apresenta, entende-se que o movimento analítico deve enaltecer a experiência local para reduzir a influência do global.

$\bigcirc$ encontro entre presente e futuro, local e global, se dá no território, por isso é fundamental compreender as diversas temporalidades específicas que que dão significado às relações de poder. Logo a análise é multidimensional, integrando atores, energia e informação, códigos, objetivos, estratégias, contexto espaço-temporal e o canal de relacionamento ou comunicação (Raffestin; Barampama, 1998).

Com base em Raffestin (1986b), acrescenta-se que a territorialidade humana se apresenta num ciclo duplo: territorial (territorialização-desterritorialização-reterritorialização TDR) e informacional (inovação-difusão-obsolescência - IDO), dinâmico e constituído de continuidade e descontinuidade, que associa grande e pequena escala. Assim, se entende que as relações com a externalidade e com a alteridade são condicionadas por mudanças que ocorrem também nos sistemas informacionais.

Portanto, as Geografias das Ausências são amplamente promovidas quando não se consideram as consequências da imposição da lógica global sobre o local. Dessa forma, não se tenciona a submissão das dinâmicas territoriais locais (TDR) ao ciclo do produto (IDO), vinculado ao global, que é concebido como promotor da modernização e associado a um projeto de futuro que visa a transformação do território. Também o território construído na dinâmica do local é desqualificado, e o presente desvalorizado em detrimento de um futuro apresentado promissor. Para enfrentar as Geografias das Ausências, é preciso expandir o presente e enaltecer o local.

Para promover as Geografia das Emergências o empenho está em contrair o futuro e reduzir a influência do global. Então parte-se da exposição das faces da modernização no território, suas consequências ambientais e sociais, bem como as estratégias adotadas no local para enfrentar os processos de TDR promovidos por atores externos, inseridos lógicas globais (IDO). Dessa forma, as emergências expõem resistências no território à imposição de ideias de futuro e projetos de desenvolvimento que são alheios ao local. No território de luta (Paula, 
2018), a Geografia das Emergências evidencia e valoriza a inesgotável experiência social que está em curso no mundo de hoje, a qual se apresenta como possibilidade de enfrentar a modernização que expõe suas faces no território.

Nesse contexto, o enfrentamento das Geografias das Ausências e a promoção das Geografias das Emergências se constituem em processos de ensino, pesquisa, extensão e atuação profissional nos quais os geógrafos questionam os limites do projeto de futuro apresentado pela modernização e expõem como contraponto as experiências e resistências no território (local), enfrentando as relações assimétricas de poder, que resultam em fascismo territorial (Santos, B., 2002).

\section{Geografias das Ausências}

Partindo da obra de Boaventura Santos (2002, 2011), propõe-se a compreensão das Geografias das Ausências, as quais se expressam na busca por "expandir o presente" enaltecendo o local. Nessa perspectiva, o local é compreendido no âmbito do território (tradicional). Assim, o cosmopolitismo subalterno se expressa na luta contra a exclusão social, econômica, política e cultural decorrente do capitalismo global, que se manifesta no território (Santos, B., 2007).

A compreensão territorial das ausências parte de Raffestin (2012), o qual destaca o papel da memória e do esquecimento na dinâmica territorial a partir dos eixos de compreensão paradigmático e sintagmático. Isso permite compreender a produção de território sobre territórios, por meio da criação e recriação de valores econômicos, culturais, sociais e políticos. Sendo assim, o novo território decorre do estabelecimento de um novo paradigma é acompanhado pela instalação de sintagmas que o evidencia. Em outras palavras, as promessas da modernização são acompanhadas da instalação de elementos no espaço que remetem ao moderno, que darão sustentação ao novo território.

Por exemplo, na pesca artesanal, Paula (2018) esclarece que a Geografia das Ausências se expõe quando os geógrafos não reconhecem ou desqualificam as comunidades tradicionais, em processos de instalação de empreendimentos sobre os seus territórios. $\bigcirc$ uso do território comunitário é considerado superado, e se propõe novos usos que são entendidos como inovadores, a partir de um padrão global. Essa proposta encontra apoio no Estado, interessado no desenvolvimento econômico, e é fomentado no âmbito dos meios de comunicação. Assim, as comunidades são apresentadas como um entrave para o estabelecimento de projetos, que são benéficos para a sociedade geral.

Boaventura Santos (2011) apresenta cinco lógicas que produzem ausências no âmbito da Sociologia. Contudo, buscando compreender essas abordagens no âmbito da Geografia das Ausências, elas serão destacadas como paradigmas que permitem o avanço e a territorialização da modernização pelo estabelecimento de ausências no território tradicional com a elaboração do ignorante, do atrasado, do inferior, do local ou particular e do improdutivo ou estéril.

\section{Paradigma do saber único}

No território, o paradigma do saber único pode ser compreendido por meio da colonialidade do saber e do poder (Quijano, 2005). Nesse sentido, o poder se estabelece a partir do desconhecimento ou da negação dos saberes de outras culturas. A eleição da ciência moderna ocidental como racionalidade superior mantém as estruturas de dominação e subalternização (Santos, B., 2002) de grupos sociais detentores de outras racionalidades e conhecimentos. 
A ideia de que o conhecimento científico é uma verdade absoluta constitui um paradigma que o elege como base para a gestão do ambiente/território. As estruturas de poder estabelecidas a partir do saber se mantêm com a submissão dos sujeitos, e do território, aos ditames provenientes da ciência moderna. Assim, as atividades promotoras da modernização, com base nos conhecimentos científicos, propõem a construção de outros territórios associados a outros usos, estabelecendo valores culturais, sociais e políticos, que indicam que tais atividades superam o uso tradicional. Na medida em que os empreendimentos se instalam, as presenças de suas infraestruturas expressam sintagmas que caracterizam o novo território. Esse território, da modernização, põe em choque os paradigmas da ciência moderna e do conhecimento tradicional. Desse processo se evidenciam marcas no território (Suertegaray, 2017), a ponto de configurar uma problemática ambiental.

Outro ponto a destacar é a administração científica da natureza. Como se sabe a crise ambiental e territorial foi amplamente gestada no âmbito do conhecimento científico, com a promoção de tecnologias de extração de recursos, industrialização etc. Contudo, diante do desconhecimento do conhecimento (Morin,1996) a própria ciência apresenta soluções, para a superação da crise que ela mesma criou. Essas soluções se expressam em normas restritivas de uso do território, que excluem sujeitos que não estão inseridos nesta racionalidade. Ressalta-se que, por não separar seus saberes dos fazeres (Morin, 2005), esses sujeitos fazem uso do território sob uma racionalidade (ambiental) (Leff, 2006) que não promoveu tal crise. Os sintagmas na gestão do território, vão se expressar em um quadro normativo que associa a estruturas de fiscalização e de controle.

\section{Paradigma do tempo sincrônico}

Milton Santos (2006) entende que no espaço coexistem diversos tempos (diacrônico). Contudo o paradigma da unicidade do tempo (sincrônico) e da história é largamente produzido, gerando ausências no/do território. A temporalidade pautada na ideia de "progresso, revolução, modernização, desenvolvimento, crescimento, globalização” (Santos, B., 2011, p. 247) não dialoga e nega as temporalidades que se expressam no território, no presente. Na perspectiva do território destaca-se que as relações de poder não se desenvolvem em um tempo único e uniforme, mas é significada por temporalidades específicas para os atores em questão (Raffestin; Barampama, 1998).

Entende-se que diversos tempos e histórias são negados resultando em ausências. Quanto às comunidades tradicionais, deve ser destacada a negação do tempo da ancestralidade na constituição dos saberes e fazeres, do tempo da natureza no uso dos recursos e do tempo histórico na apropriação do território (poderiam ser citados outros vários)

Destaca-se que há uma temporalidade estimável, mas incomensurável do ponto de vista da constituição dos modos de viver no território. Essa temporalidade se manifesta no presente como o tradicional, contudo está sempre em movimento. Logo, expõe saberes e práticas nos processos em curso, mas que foram constituídos a partir de gerações, transmitidos principalmente por meio da oralidade. Esse tempo se expressa no uso do território tradicional, e se expõe nos sintagmas que evidenciam a conservação do mesmo. 
Contudo, esse tempo é negado quando tais saberes e práticas são confrontados com paradigmas científicos, cujos dados não os corroboram. Nesse sentido, o desconhecimento da complexidade temporal/histórica de constituição dos saberes, que se manifestam no presente, é a principal causa do seu desprestígio. A ancestralidade é concebida como resquícios de um passado, quando concebida por métodos científicos modernos, que só concebem a história como uma reta normal linear. Contudo, a ancestralidade nos saberes e fazeres retoma o passado, ressignifica o presente em que se expõe, sempre considerando as possibilidades de futuro do território tradicional.

A segunda temporalidade que é negada diz respeito à congruência entre tempo da natureza e tempo da comunidade. Isso contrasta com o paradigma da modernização, cujo tempo de uso da natureza está cada vez mais subordinado ao da sociedade, e entende a permanência de sujeitos sociais cujas temporalidades estão associadas à dinâmica do ambiente como atrasados. Ressalta-se que esse tempo não diz respeito somente à produção, mas está relacionado com toda a dinâmica social das comunidades, que Milton Santos (2006) denomina "tempo lento" e que se expressa no território. No entanto, na medida em que essas temporalidades são desqualificadas, os argumentos colaboram para imposição no território de processo, cujo tempo está associado ao tempo da máquina. Os sintagmas que marcam o território da modernização, nesse caso, se expõem como oposição ao natural.

A terceira temporalidade que deve ser enfatiza diz respeito ao tempo histórico de apropriação do território. Esse tem constituído um dos principais argumentos que garantem a presença das comunidades nos territórios tradicionais. Contudo costumeiramente é desconsiderado nos contextos em que a modernização ou outros projetos do Estado avançam sobre os territórios tradicionais. A produção de ausências está associada ao discurso que defende o paradigma da promoção do progresso, com a instalação de estruturas (sintagmas) que expõem a modernização do território. Disso resulta na destruição do ambiente e/ou uso do território ocupado historicamente pelas comunidades em condições de sustentabilidade. Nesse sentido a ocupação histórica do território, no presente é tratada como um vínculo indesejado com o passado e uma barreira para avanços futuros.

\section{Paradigma da inferioridade de grupos e territórios}

$\bigcirc$ paradigma da inferioridade de grupos consiste na produção hierarquias e expressam no território. Assim é importante frisar que no âmbito das Geografias das Ausências, a naturalização das diferenças, sustenta a noção de inferioridade dos grupos sociais e seus territórios, o que está por trás do racismo ambiental.

Da hierarquia das classes e grupos sociais, vê-se derivar a constituição da hierarquia do acesso ao território. Essa encontra no argumento econômico um dos principais fatores, que é bem aceito no campo político. Além disso, a ideia de modernização dos territórios das comunidades tradicionais, muitas vezes produzida em campanhas publicitárias, parece agradar os seguimentos da sociedade que aspiram ao acesso a tais recursos acrescidos de infraestruturas modernas, sem considerar o contexto de fascismo territorial a que as comunidades locais são submetidas. 
Entende-se que os processos de construção, desconstrução e reconstrução, funcionalização, desfuncionalização e refuncionalização dos territórios (Raffestin, 2012) são seletivos. Esses não ocorrem em territórios dominados por sujeitos sociais detentores de poder econômico e político, mas em territórios apropriados por grupos considerados vulneráveis socialmente. Sendo assim, a instalação de empreendimentos não leva em conta apenas o aspecto locacional, mas a população que será afetada (população negra, comunidades tradicionais etc.), cuja falta de acesso a direitos básicos pode implicar remoções arbitrárias, pagamento de indenizações irrisórias e pouca queixa (judiciária) frente a tais impactos.

Diante disso, as comunidades tradicionais veem o avanço da modernização, cujos empreendimentos fazem uso dos recursos acima de sua possibilidade de renovação ou que têm outros impactos como poluição e contaminação de corpos d'água, solo ou ar. Além disso, na atualidade, inserem atores que não reconhecem a dinâmica social, provocando tensões nas comunidades. Esses empreendimentos são permitidos, pois não se consideram seus impactos nas comunidades locais ou seus modos de viver. Logo, se realizam presumindo a superioridade dos atores detentores do capital sobre as comunidades locais, com o apoio do Estado.

Destaca-se que o paradigma de uso do território pelas comunidades tradicionais permitiu a manutenção das condições ambientais relativamente em equilibrio. Contudo, esses espaços com paisagens de beleza natural são cada vez mais raros. Assim, a modernização avança sobre os mesmos propondo a refuncionalização, com instalação de infraestruturas que interessam às elites econômicas e políticas. Já os comunitários são paulatinamente desterritorializados, por não terem acesso a tais infraestruturas e serviços, e terem suas atividades regulamentadas a partir de lógicas que são externas ao território tradicional. Em muitos casos, para viabilizar a modernização, o Estado viabiliza a remoção dessas comunidades de seus territórios ancestrais, com argumentos de que os mesmos são áreas degradadas, de insegurança ambiental etc.

\section{Paradigma da superioridade do global}

O paradigma da superioridade do global, no âmbito da modernização, também é responsável pela produção de ausências no território. Com a modernização, o global foi eleito como escala dominante, que orienta a relevância das demais escalas. Disto a importância da escala local, na qual se encontram os territórios tradicionais, é minimizada frente aos interesses do global. Para Boaventura Santos (2011), isso se apresenta como universalismo, ou seja, na predominância de escalas independentemente de contextos específicos.

Nesse sentido a dinâmica territorial está cada vez mais sujeita à escala global. Isso se evidencia na influência das redes globais de tomadas de decisões que promovem a modernização sobre territórios tradicionais. Assim, as comunidades se veem sujeitas às dinâmicas, aos processos e às tecnologias que são alheias ao local, e que não correspondem à realidade ambiental e social presente nos territórios tradicionais.

Contudo é fundamental que a decisão locacional de instalar essas atividades promotoras da modernização sobre territórios tradicionais, devem-se ao interesse dos países centrais de transferirem seus impactos e conflitos para países periféricos. Ressalta-se que o Estado viabiliza a promoção da lógica global sobre o local, por meio da modernização. Ainda oferece os meios necessários para a instalação dos sintagmas da modernização, que estabelecem o novo 
território, mesmo reconhecendo o custo ambiental e social desse avanço. Nesse processo, que se apresenta como um regresso colonizador, as comunidades são desassistidas pelo Estado, que não reconhece o uso tradicional do território.

Diante disso, o local é compreendido como incapaz de apresentar alternativas viáveis às propostas do global. Os arranjos territoriais das comunidades tradicionais não são reconhecidos, nem suas práticas de gestão comunitária do território. Frente ao global, o local é apresentado como impossibilidade de futuro.

\section{Paradigma do produtivismo}

$\bigcirc$ paradigma do produtivismo expõe os critérios de produtividade capitalista e constitui elemento fundamental para a compreensão da produção de ausências pela modernização nos territórios tradicionais. Este pressupõe que o crescimento/desenvolvimento econômico constituem o objetivo inquestionável, o que viabiliza a promoção dos territórios da modernização. Logo, nega-se que o território é multidimensional, integrando dimensões culturais, sociais, econômicas, políticas, ambientais e muitas outras.

Ressalta-se que os critérios de produtividade dizem respeito tanto à natureza quanto ao trabalho humano (Santos, B., 2002). Em relação à natureza, o meio encontrado é a potencialização dos seus processos por meio do emprego de ciência e tecnologia. Quanto ao trabalho isso se expressa na submissão dos trabalhadores aos ritmos de produção cada vez mais associados ao funcionamento das máquinas e às demandas do consumo. Isso tem resultado em desprestígios a atividades, sujeitos, grupos e territórios associados ao setor primário, especialmente aqueles que estão mais vinculados aos tempos da natureza.

Outra problemática que vai se expressar nos territórios tradicionais é a relação entre trabalho urbano e trabalho rural. Cada vez mais os trabalhadores rurais vão ser estimulados a intensificarem seus processos para atender as demandas da sociedade urbana. Esta última já está sujeita aos processos de produtividade da modernização, então vão cobrar maior produção do trabalho rural. Os trabalhadores rurais que não se submetem a esses contextos, assim como seus territórios, serão considerados improdutivos. Dessa forma, a própria lógica de produção e consumo do urbano se impõem sobre as comunidades que estabelecem outras relações com o território.

O estímulo à intensificação da produção será uma demanda da sociedade geral, interessada no consumo, e do Estado, que deseja o desenvolvimento econômico. Outras vezes, o Estado vai fomentar a substituição da atividade tradicional por outras atividades econômicas que promovam a modernização do território, cujos padrões de produtividade são superiores. Isso vai implicar na constituição de um território completamente adverso ao tradicional, e as múltiplas dimensões se resumem à econômica. Nesse sentido o paradigma do produtivismo, acompanha elementos ou sintagmas que funcionam como próteses no território para o estabelecimento de processos que visam a maior produção possível.

Tendo compreendido os paradigmas que promovem ausências e permitem o avanço da modernização sobre os territórios tradicionais, na sequência será apresentado o processo a promoção de emergências, por meio da retomada da autonomia nos territórios tradicionais. 


\section{Geografias das Emergências}

Para Boaventura Santos (2002), enquanto a Sociologia das Ausências evidencia o que é ativamente produzido como não existente, na Sociologia das Emergências a ausência exprime possibilidades futuras, ainda por identificar e uma capacidade ainda não plenamente formada para ser executada.

Na leitura geográfica que faz da Sociologia das Emergências, Boaventura Santos (2002, 2011) propõe destacar possibilidades e estratégias para recuperar a autonomia das comunidades no território tradicional. Nesse caso, as Geografias das Emergências contraem o futuro e reduzem a influência do global. Logo, expõem disputas de futuro com base nas expectativas sociais, que visam o enfrentamento do avanço da modernização sobre o território, e a recuperação da autonomia. Assim, as ausências são convertidas em instrumentos de luta, resistência e reivindicação, como possibilidades de futuro.

Seguindo a perspectiva de Raffestin (1986a), a autonomia é fundamental na territorialidade humana. Para o autor, os extrativistas apresentam uma estreita relação entre autonomia e território. Logo, a ecogênese territorial integra as noções de limite, centralidade no local da coleta e circulação. $\bigcirc$ território delimitado constitui a reserva, fundamental para autonomia, e se mantém por meio da comunicação, que representa o cerne dos processos de TDR. Dessa forma, a permanência do grupo depende da manutenção dessa autonomia.

Nesse contexto, as Geografias das Emergências expõem as realidades que estavam silenciadas, suprimidas e marginalizadas na produção de ausências no território, produzidos pela imposição da lógica global. Nessa linha de análise, compreendem-se Boaventura Santos (2002, p. 253) e a necessidade de "imaginação epistemológica e democrática". Assim, a imaginação epistemológica proporciona a diversificação dos saberes, perspectivas e escalas de identificação, análise e avaliação das práticas. Já a imaginação democrática favorece o reconhecimento das diferentes práticas e atores sociais.

Para a "ampliação simbólica" - grande atenção que se deve dar ao que foi negligenciado -, Boaventura Santos (2002) propõe dois procedimentos: tornar menos parcial o conhecimento das condições do possível para conhecer melhor as realidades investigadas, e tornar menos parciais as condições do possível para fortalecer as pistas e sinais. Logo, devem ser evidenciados os sinais, pistas e tendências latentes, que mesmo dispersas, embrionárias e fragmentadas expõem a "constelação de sentidos" sobre a compreensão e a transformação do mundo (Santos, B., 2007). Esses contextos da globalização, Milton Santos (2006) os compreende como solidariedades estabelecidas a partir do local.

Estabelecendo o diálogo entre abordagens da Geografia e denúncias do movimento social, Paula (2018) apresentou as faces da modernização que se expõem no território em contextos de luta como argumento e estratégia de recuperação da autonomia do território tradicional. As faces da modernização correspondem a uma estratégia de análise, das muitas possíveis, de enfrentamento às ausências geradas na modernização, para expor um "futuro simultaneamente utópico e realista". Assim, parte de "realidades concretas", e ampliando o presente agrega o "real amplo", ou seja, as possibilidades e esperanças de futuro que ele comporta (Santos, B., 2002). Os enfretamentos e contrapostos à modernização que evidencia suas faces no território, constituem estratégias para a recuperação da autonomia no território, e se evidenciam nas Geografias das Emergências. 
Na pesca artesanal, por exemplo, as Geografias das Emergências se evidenciam quando se abre espaço para as comunidades, reconhecendo seus saberes e fazeres como alternativas para a superação da crise ambiental e promoção de outras formas de desenvolvimento e gestão do território. Essas constituem possibilidade de enfrentamento ao avanço da modernização, que são consequências das ações do global sobre o local, por meio de processos informacionais, e resultam na degradação ambiental, sobre-exploração e limite de acesso aos pesqueiros, e expropriação da terra. Frente a esses processos devem ser expostas as resistências das comunidades, pela adesão ao projeto de comunidades e povos tradicionais, mobilização em movimento social, e constituição de um território de luta (Paula, 2018).

Como contraponto à monocultura das ausências, Boaventura Santos $(2002,2011)$ apresenta as ecologias das emergências. Nessa leitura geográfica, o contraponto é estabelecido entre os paradigmas dos territórios da modernização, em contraste com a promoção de autonomia dos territórios tradicionais. A promoção da autonomia se dá no âmbito dos saberes, das multitemporalidades, dos reconhecimentos das diferenças, da escala do local e da produção tradicional.

\section{Autonomia nos saberes}

Para enfrentar o paradigma do saber único na constituição dos territórios da modernização, propõem-se a promoção da autonomia do território tradicional com a valorização dos diversos saberes, especialmente os tradicionais. Isso significa reconhecer e credibilizar os saberes tradicionais "territoriais" na gestão ambiental e territorial, bem como promover diálogos de saberes.

Nesse sentido, valoriza-se a constituição dos saberes na escala local, bem como a viabilidade destes para pensar a gestão do território no presente. Entende-se que quanto mais os saberes tradicionais forem a base da gestão do território tradicional, maior será a autonomia deste último. Assim, enfrentam-se os desígnios do global sobre o local, bem como se embatem os processos de tomada de decisão baseados unicamente no conhecimento científico moderno.

Nesses diálogos e disputas epistemológicas (Santos, B., 2002, 2007), cada saber contribui com o diálogo e com a superação da ignorância. Contudo, é fundamental reconhecer a pluralidade de conhecimentos heterogêneos, e a interação entre eles não deve comprometer a autonomia de cada um; assim, o conhecimento é interconhecimento (Santos, B., 2007).

Logo, não se trata de reproduzir a unicidade do conhecimento, no saber tradicional, mas de superar a situação de subalternidade destes. Nesse sentido, o diálogo deve ser consciente de o que está sendo aprendido, e o que é desaprendido, pois no interconhecimento se aprende com os outros sem esquecer os próprios saberes. Os conhecimentos científicos devem ser apropriados então numa perspectiva contra-hegemônica. Nesse diálogo, deve também ser enfatizado que o conhecimento científico se apresenta repleto de incertezas, que quando não reconhecidas em perspectivas complexas, promove usos e aplicações de tecnologias, concebidas no global, que têm consequências irreversíveis (Santos, M., 2006), principalmente no local.

Ao enfatizar os saberes das comunidades locais na gestão do território tradicional, a Geografia concorre para promover "contraepistemologias" (Santos, B., 2007). Logo, expõe diversas alternativas plurais para enfrentar o capitalismo global, que, por meio da modernização, avança sobre os territórios tradicionais. 


\section{Autonomia nas multitemporalidades}

Para resistir ao paradigma do tempo sincrônico, que impõe a modernização sobre o território, propõe-se a autonomia do território por meio da promoção das multitemporalidades. Entende-se que o tempo linear é o tempo da modernidade, que submete as demais temporalidades ao tempo do global (Santos, B., 2007). Nos territórios tradicionais se expressam diversas temporalidades, como a da ancestralidade, da relação com a natureza, da ocupação histórica.

Ressalta-se que a superação das hierarquias a partir da temporalidade dominante do global reduz a influência do poder do global sobre o local. Assim, o território passa a expressar diversas temporalidades vinculadas ao local, e o reconhecimento das temporalidades faz com que as práticas sociais deixem de ser consideradas resíduos, ganhando forma para o desenvolvimento autônomo (Santos, B., 2002) do território.

Uma evidência disso são as práticas sociais vinculadas aos tempos da natureza, que, sendo reconhecidas na dinâmica do território, proporcionam a gestão dos recursos sem comprometer a sustentabilidade. Ressalta-se que, no local, as temporalidades da natureza, além do manejo dos ecossistemas, têm grande influência sobre os modos de viver.

Também cabe destacar a compreensão da simultaneidade de tempos, como aponta Milton Santos (2006). Assim, a ancestralidade não é concebida como um resquício do passado, mas corresponde a uma forma de viver no presente. Esta, assim como a temporalidade de ocupação e uso do território, passa então a ser consideradas na argumentação e disputa política (Santos, B., 2002).

Boaventura Santos (2007) esclarece que compreender a moldura temporal para além da duração da ação do Estado tem evidenciado, em experiências subalternas do Sul, respostas às necessidades imediatas de sobrevivência e de longa duração frente ao capitalismo e ao colonialismo. Assim, reconhecer as inúmeras temporalidades que se expressam no território tradicional expõe emergências, na medida em que apresenta propostas que a temporalidade da globalização não é capaz de proporcionar.

\section{Autonomia na diferença}

Para a autonomia do território tradicional, superando o paradigma da inferioridade de grupos e territórios, propõe-se a promoção do reconhecimento das diferenças. Para isso tem-se que superar a colonialidade do poder que entende diferença como desigualdade, bem como se entende com a prerrogativa de apontar os diferentes. Dessa forma, faz-se necessário articular os princípios da igualdade e da diferença. Assim, quando desaparecem as hierarquias, permanecem as diferenças que a hierarquia necessita para se manter (Santos, B., 2002).

Na leitura das Geografias das Emergências se entende que devem ser enfrentadas as desqualificações dos sujeitos, práticas, saberes e territórios. Isso porque as hierarquias constituídas no global se impõem no local, e expressam desigualdades no território. Isso também faz com que determinados territórios sejam preferidos para a instalação de empreendimentos da modernização que são potencialmente causadores de danos ambientais e sociais.

Para enfrentar essas diferenças propõem-se a que a hierarquia entre sujeitos e territórios seja convertida em reconhecimentos. Nesse sentido, em contraponto à homogeneidade que o global propõe, propõe-se a valorização da heterogeneidade dos territórios, cujas diferenças se 
expressam nos saberes e fazeres, modos de viver, cultura. Além disso, o devido reconhecimento tente a reservar tais territórios para esses usos tradicionais, significando um obstáculo para o avanço da modernização.

Na promoção dos territórios da diferença, que se apresenta como território de direitos específicos, é fundamental a garantia da manutenção dos modos de viver, que se reinventa no processo de luta por territórios. Por isso, deve ser promovida ampla participação, desde o reconhecimento, que deve ser baseado na autoidentificação das comunidades tradicionais, até os usos que devem estar pautados na gestão comunitária do território.

A autonomia do território tradicional se manifesta quando externamente o território deixa de ser visto como inferior, passando a ser compreendido como prioritário no que tange a determinadas políticas. E quando internamente as diferenças hierárquicas são suprimidas, por meio de processos participativos e democráticos de gestão, que viabilizam a promoção dos modos de viver tradicional. Ressalta-se que esses modos de viver não devem ser tomados como estáticos, mas em processo contínuo de transformação, cuja essência se expressa nos vínculos comunitários, com o ambiente e território.

\section{Autonomia na escala local}

Entende-se que para a autonomia dos territórios tradicionais é fundamental afrontar o paradigma da superioridade do global, por meio da valorização da escala local (território). Para isso, Boaventura Santos $(2002,2007)$ entende que se deve identificar no local o que não foi integrado na globalização hegemônica, bem como proporcionar a (des)globalização do local.

Para a autonomia do território tradicional, é fundamental reconhecer os efeitos da globalização internos e externos ao mesmo. Internamente o empenho deve estar em garantir a manutenção e resgate de saberes e práticas que não estão vinculadas ao global. Também é fundamental proporcionar a gestão do território a partir da dinâmica do local, reconhecendo as práticas de governança. Ainda deve-se identificar o que já está associado ao global e ressignificá-lo a partir do local, servindo de contraponto ao global.

A autonomia frente aos efeitos externos da globalização, nesse caso, depende do reconhecimento e salvaguarda do território tradicional, para inibir o avanço das atividades da modernização. Além disso, por meio de políticas públicas, deve-se promover a sustentabilidade do território tradicional. Assim, o território tradicional corresponde ao outro da globalização, que pode expor questionamentos e alternativas para a sociedade geral quanto os efeitos nocivos da globalização.

É também fundamental compreender a necessidade de converter o papel do Estado como mediador entre global e local. Se a crítica estabelecida é a de que o Estado viabiliza a expressão do paradigma da globalização no território, entende-se que ele pode promover o local no território, o que Milton Santos (2006) chama de "uma outra globalização".

Ressalta-se a escala do local como a possibilidade de um contraponto à globalização, que se realiza na constituição de territórios tradicionais, que não aderem ao projeto global, e ressignificam os elementos do global no local, promovendo uma outra globalização. Esta visibiliza sujeitos sociais e territórios, que não eram possíveis no contexto de homogeneização promovido pelo global. 


\section{Autonomia na produção tradicional}

Finalmente entende-se que para a autonomia do território tradicional é necessário enfrentar o paradigma produtivismo e promover formas tradicionais de produção. Entende-se que essas formas tradicionais de produção foram mantidas no capitalismo global, contudo de forma desqualificada para a manutenção da relação de subalternidade.

Assim, para a recuperação da autonomia do território tradicional se faz necessário pensar a produção a partir do local, valorizando as atividades tradicionais, bem como relações e sistemas de produção alternativos. Ainda, deve-se questionar os limites do desenvolvimento econômico, sobretudo evidenciando suas consequências na escala do local.

Ressalta-se que no caso das comunidades extrativistas constitui um equívoco considerar que não há produção, mas somente extração. No mínimo, é excessivamente simplificadora essa compreensão, que limita essas atividades à coleta ou à captura. Entende-se que a produção nas atividades extrativistas corresponde a uma complexa cadeia, que integra múltiplos atores, bem como saberes e fazeres constituídos no âmbito comunitário ao longo de gerações. Sendo assim, para a autonomia do território é fundamental que sejam garantidas as diversas territorialidades que integram a produção tradicional.

Além disso, é fundamental reconhecer a pluriatividade das comunidades tradicionais, para garantir que os processos produtivos estejam de acordo com os ritmos e ciclos da natureza. Como já foi apresentado, a falta de garantia do território para a realização de diversas atividades que correspondem a produção nos modos de viver tradicional, resulta na deterioração desses últimos e emprego de técnicas que provocam danos no ambiente.

A relação entre uso do território e condição de sustentabilidade da natureza, além de valorizada, deve constituir argumento para garantir e salvaguarda de tais territórios tradicionais. Sendo assim, em vez de depreciada a lógica de produção artesanal, em consonância com a dinâmica ambiental deve ser valorizada e concebida como alternativa local para o enfrentamento da crise ambiental concebida no global e que se expressa no território.

A promoção da produção tradicional no território também valoriza as comunidades como provedoras de alimento para a sociedade geral. Contudo essas comunidades não devem perder a autonomia do território tendo a produção condicionada à dinâmica do consumo dos centros urbanos ligados à lógica global, que promete o acesso de todos a qualquer produto em qualquer lugar. Isso promove para além do território a discussão sobre os padrões de consumo, na qual a valorização das condições da natureza tende a se expressar em variedades segundo sazonalidades, estimulando a produção e o consumo segundo suas safras, bem como conscientizando quanto ao desperdício e à necessidade de racionamento em determinados períodos.

\section{Considerações finais}

Em Geografia(s) da pesca artesanal brasileira, Paula (2018) compreende que a Geografia brasileira tem promovido ausências no que tange aos pescadores artesanais e seus territórios. Assim, reforça invisibilidades sociais e concorre para a manutenção da vulnerabilidade desses sujeitos frente ao avanço das atividades da modernização que causam impacto ambiental, disputas no território e conflitos por território. Em diálogo com os movimentos sociais da pesca artesanal, entende-se que esses contextos de pesquisa põem em evidência as faces da modernização: degradação, sobre-exploração e restrição ao acesso, expropriação da terra. 
A partir dessa discussão, o caminho adotado foi estabelecer o diálogo entre a Sociologia das Ausências e a Sociologia das Emergências, de Boaventura Santos, e o processo de TDR, de Claude Raffestin. Assim, é fundamental destacar que a abordagem epistemológica que se estabelece tem centralidade nas compreensões sobre modernização, tradicionalidade e território, ou seja, que, nas discussões que envolvem o embate entre o uso (tradicional e moderno) do território, a Geografia não é neutra.

As Geografias das Ausências se colocam junto ao "dominante", aquele que tem a prerrogativa do poder político e econômico. Ela está muito influenciada pelos meios de comunicação, que reforçam os paradigmas da modernização. Mesmo que intencionalmente ela não esteja comprometida com excluir sujeitos sociais, toma como referências conceitos e índices que reduzem esses sujeitos a nada. Assim, esse fazer Geografia julga contribuir para a sociedade geral, impregnada da necessidade de progresso, avanço e desenvolvimento (para todos ou para alguns) dentro de padrões globais de produção e consumo. Os paradigmas da modernização estão presentes implícita ou explicitamente nesse discurso geográfico, que elabora compreensões de que determinados sujeitos e/ou territórios são ignorantes, atrasados, inferiores, local ou particular e improdutivo ou estéril.

As Geografias das Emergências vislumbram o local como possibilidade de reação aos impactos do global. Revertem o discurso que culpabiliza e criminaliza as comunidades e encontram nelas, no presente, alternativas para um futuro. A experiência do local expõe nessas Geografias a necessidade de recuperação da autonomia no território, desenvolvendo práticas adequadas aos saberes constituídos a partir de relações sociais e com a natureza, e não se submetendo aos ditames do global. As emergências dessas Geografias se apresentam em um processo contínuo de combina resistência e re-existência, pois exige que tais sujeitos se reinventem como comunidades tradicionais para a conformação e a defesa de um território de luta. A recuperação da autonomia se dá no reconhecimento dos saberes, das multitemporalidades, das diferenças, da escala do local e da produção tradicional.

Diante do exposto, compreende-se que a Geografia brasileira, no século XXI, em sua pluralidade, deve se questionar sobre os usos que serão feitos dos conhecimentos que produz. Dessa forma, pode (ou não) evitar a produção de ausências e se comprometer em evidenciar emergências de sujeitos e territórios.

\section{Referências}

BARDIN, L. Análise de conteúdo. São Paulo: Edições 70, 2011.

CASTRO-GÓMEZ, S. Ciências sociais, violência epistêmica e o problema da "invenção do outro". In: LANDER, E. (Org.). A colonialidade do saber: eurocentrismo e ciências sociais - perspectivas latino-americanas. Buenos Aires: Títulos, Paula (2018)del Programa Sur-Sur/Clacso, 2005. p. 80-87. 
LEFF, E. Racionalidade ambiental: a reapropriação social da natureza. Trad. Luís Carlos Cabral. Rio de Janeiro: Civilização Brasileira, 2006.

MORIN, E. O Método 6: ética. Porto Alegre: Sulina, 2005.

MORIN, E. Ciência com consciência. Trad. Maria Alexandre e Maria Alice Sam. Rio de Janeiro: Bertrand Brasil, 1996.

MORIN, E. Introdução ao pensamento complexo. Lisboa: Instituto Piaget, 1990.

PAULA, C. Q. Geografia(s) da pesca artesanal brasileira. Tese (Doutorado em Geografia) - Instituto de Geociências, Universidade Federal do Rio Grande do Sul, Porto Alegre, 2018.

QUIJANO, A. Colonialidade do poder, eurocentrismo e América Latina. In: LANDER, E. (Org.). A colonialidade do saber: eurocentrismo e ciências sociais - perspectivas latino-americanas. Buenos Aires: Títulos del Programa Sur-Sur/Clacso, 2005. p. 107-130.

RAFFESTIN, C. Space, territory, and territoriality: environment and planning. Society and Space, v. 33, p. 121-141, 2012.

RAFFESTIN, C. Ecogenèse territoriale et territorialité. In: AURIAC, F ; BRUNET, R. Espaces, jeux et enjeux. Paris: Fayard/Fondation Diderot, 1986a. p. 175-185

RAFFESTIN, C. Punti di riferimento per una teoria della territorialità umana. In: COPETA, C. Esistere e abitare: prospettive umanistiche nella geografia francofona. Milano: Franco Ageli, 1986b. p. 75-89.

RAFFESTIN, C.; BARAMPAMA, A. Espace et pouvoir. In: BAILLY, A. Les concepts de la géographie humaine. Paris: Armand Colin, 1998. p. 63-71.

SANTOS, B. S. Epistemologías del Sur. Utopía y Praxis Latinoamericana, v. 16, n. 54, p. 17-39, 2011.

SANTOS, B. S. Para além do pensamento abissal: das linhas globais a uma ecologia de saberes. Revista Novos Estudos Cebrap, n. 79, p. 71-94, 2007.

SANTOS, B. S. Para uma sociologia das ausências e uma sociologia das emergências. Revista Crítica de Ciências Sociais, n. 63, p. 237-280, 2002.

SANTOS, B. S.; MENESES, M. P. G.; NUNES, J. A. Conhecimento e transformação social: por um a ecologia de saberes. Hiléia - Revista de Direito Ambiental da Amazônia, n. 6, p. 11-104, 2006.

SANTOS, M. A natureza do espaço: técnica e tempo, razão e emoção. 4a ed. 2a reimpr. São Paulo: Edusp, 2006.

SILVA, C. A. S. Sobre a Geografia das Existências. In: SILVA, C. A. S.; PAULA, C. Q. (Org.). Brasil e Moçambique: diálogos geográficos sobre a pesca artesanal. Rio de Janeiro: Consequência, 2016. p. 17-32. 
SUERTEGARAY, D. M. A. Religar a geografia: natureza e sociedade. Porto Alegre: Compasso Lugar-Cultura, 2017.

TOMÁZ, A. F; SANTOS, G. (Org.). Conflitos socioambientais e violações de direitos humanos em comunidades tradicionais pesqueiras no Brasil. Brasilia, DF: Conselho Pastoral dos Pescadores, 2016. 